\section{Confidencialidade, aconselhamento genético e saúde pública: um estudo de caso sobre o traço falciforme}

\author{
Confidentiality, genetic counseling, and public \\ health: a case study on sickle cell trait
}

\begin{abstract}
Sickle cell anemia is the most prevalent genetic disease in Brazil. Screening for sickle cell trait in blood donation centers has been recommended by the Brazilian government since 1976. This screening mechanism is one of most common forms of genetic screening for sickle cell disease in the country. This article is based on an ethnographic survey of individuals undergoing genetic counseling in a large blood donation center. The article contends that confidentiality should be a prerequisite for the broad dissemination of genetic information in public health. The ethical principle of confidentiality needs to be seen as a human right and public health issue.
\end{abstract}

Sickle Cell Anaemia; Genetic Counseling; Bioethics
Debora Diniz 1,2

Cristiano Guedes 1,2

\section{Introdução}

O Brasil possui poucas ações no campo da genética em saúde pública. Grande parte dos centros de testagem e aconselhamento genético estão localizados nos hospitais universitários, em alguns hospitais públicos dos grandes centros urbanos e nos centros de referência para a doação de sangue. Tendo em vista que o aborto por anomalia fetal, no Brasil, é crime, as sessões de aconselhamento genético ocorrem, preferencialmente, no período neonatal para fins de diagnóstico ou de planejamento reprodutivo futuro, ou em centros de doação de sangue após a realização dos exames compulsórios pré-doação. Os protocolos de triagem para os doadores de sangue incluem, além de exames para doenças infectocontagiosas, testes para determinadas alterações genéticas que interferem na qualidade do sangue, como é o caso do traço falciforme.

Os centros de doação de sangue têm como objetivo principal a captação, o registro, a triagem clínica e a coleta de sangue para o atendimento de pessoas que necessitam de transfusão ou mesmo de algum produto hemoderivado. Alguns centros de doação, entretanto, acumulam outras competências, como a testagem, o processamento, o armazenamento, o transporte e a distribuição do sangue na rede de saúde pública e privada da região onde se localiza. No Brasil, a doação de sangue foi regulamenta- 
da como uma expressão de solidariedade em 1950 e, desde então, sua comercialização é proibida 1 .

Desde 1976, recomenda-se a inclusão da testagem de hemoglobinas no protocolo de exames para a doação de sangue no Brasil 2. Esta década foi um período em que a informação genética sobre o traço e a anemia falciformes se popularizou no mundo, especialmente em decorrência dos programas de screening genético dos Estados Unidos e de Cuba 3,4,5,6,7. Os abusos e erros cometidos pelo programa estadunidense foram pouco discutidos sobretudo pelos estudos bioéticos brasileiros, não havendo, até meados dos anos 90, qualquer programa oficial de saúde pública voltado para a anemia falciforme. Em 1996, o governo instituiu um grupo de trabalho responsável pela elaboração do Programa Anemia Falciforme (PAF), cujo objetivo principal é, por meio de atendimento em saúde especializado e ações educativas, promover a qualidade de vida das pessoas portadoras da anemia falciforme.

O aconselhamento genético vem sendo considerado um ato médico no Brasil, e o número de geneticistas treinados para a prática do aconselhamento é ainda bastante restrito ${ }^{8}$. Fora dos hospitais universitários ou dos centros de saúde pública de referência, não se encontram geneticistas treinados no ethos do aconselhamento genético, fazendo com que a informação genética seja repassada por outros profissionais de saúde também sem treino específico para o aconselhamento genético 9 . Esse é o caso da maioria dos centros de doação de sangue onde são feitos os exames pré-doação. Alguns testes genéticos são considerados parte do protocolo médico de rotina, composto por exames de sífilis, hepatite, doença de Chagas, malária ou HIV/AIDS, desconsiderando-se as especificidades da informação genética 10.

Este artigo descreve o processo de exame e aconselhamento genético para o traço falciforme de um centro público de doação de sangue no Distrito Federal. A identidade do centro será mantida em sigilo, uma recomendação ética do colegiado do Comitê de Ética e Direitos Humanos em Pesquisa que avaliou o projeto antes de sua execução. Para se ter uma idéia da representatividade dos dados etnográficos, esse centro é responsável também pela testagem de sangue doado em sete outros centros de coleta públicos, atendendo, direta ou indiretamente, uma média total de 260 doadores por dia, segundo dados de 1998.

Os dados etnográficos foram levantados em duas ocasiões. A primeira durante um trabalho de campo de cinco meses, desenvolvido no ano de 2001, em que um dos autores acompanhou dez sessões coletivas de aconselhamento genético 11. A segunda fase do levantamento ocorreu, em 2003, pela nomeação de um dos autores como assessor em um processo sobre a denúncia de infrações éticas no manuseio da informação genética pelo mesmo centro (Diniz D. Parecer ao Ministério Público do Distrito Federal e Territórios; 2004). O objetivo da descrição etnográfica é mostrar a centralidade que o princípio da confidencialidade deve ocupar em qualquer programa de aconselhamento genético. O pressuposto de nossa argumentação é o de que a informação genética diz respeito à dignidade, à identidade e à integridade da pessoa e que, por isso, deve ser mantida sob sigilo. A ausência de um acordo sobre esses princípios éticos pode representar uma ameaça aos direitos humanos e à saúde pública.

\section{O traço falciforme e a doação de sangue}

No Brasil, o traço falciforme é uma característica genética prevalente em virtude, principalmente, da quantidade de negros na população e do processo de miscigenação ${ }^{12}$. Os estudos entre doadores de sangue mostram que a prevalência do traço falciforme é maior em Estados da Região Nordeste, como é caso da Bahia, onde há maior presença de negros, e o traço falciforme é encontrado em $5,5 \%$ da população doadora de sangue, ao contrário, por exemplo, de cidades nas regiões Sul e Sudeste do país, onde a quantidade de negros é menor e, conseqüentemente, diminui a prevalência do traço falciforme 13,14. O traço falciforme, no entanto, é encontrado em todas as regiões brasileiras, e, por isso, a anemia falciforme é considerada uma das doenças genéticas mais importantes no cenário epidemiológico brasileiro 15 .

Em decorrência da presença epidemiológica da anemia falciforme, várias estratégias vêm sendo propostas pelo governo brasileiro como meio de enfrentar a doença nos últimos anos. Independentemente da qualidade das estratégias adotadas no Brasil, é possível observar que grande parte das políticas de saúde direciona suas ações educativas às pessoas portadoras do traço falciforme mais do que aos doentes da anemia falciforme 16. Essa escolha tem um caráter preventivo e que contorna a legislação brasileira sobre o aborto, ao mesmo tempo em que reconhece as limitações das terapias gênicas, pois ainda não é possível curar a anemia falciforme. Homens e mulheres portadores do traço falciforme, muito embora saudáveis, são 
considerados potenciais geradores de crianças com a anemia falciforme, por isso, o esforço sanitário em identificá-los e orientá-los quanto ao risco genético, antes mesmo que iniciem seus projetos reprodutivos 17,18. E é no contexto desse esforço sanitário para prevenir a anemia falciforme que práticas de aconselhamento genético nos centros de doação de sangue crescem no Brasil.

O estudo etnográfico realizado sugere que os centros de doação de sangue vêm se convertendo em espaços estratégicos para se identificar pessoas portadoras do traço falciforme e orientá-las quanto aos cuidados a serem adotados para reduzir a prevalência da anemia falciforme no Brasil. O curioso desse processo é que, muito embora no ano de 1970 já se projetasse a prevalência da anemia falciforme no país, a principal razão da implementação do teste genético no protocolo de doação de sangue era a garantia da saúde do receptor. Ainda hoje, o argumento de que o sangue com hemoglobinas AS apresenta restrições para a doação é válido para a medicina 19 . Não são todas as pessoas que podem receber sangue com a hemoglobina AS, pois esse apresenta alterações incompatíveis com determinados quadros clínicos 20,21.

Atualmente, o teste genético para a identificação do traço falciforme apresenta uma outra justificativa e, para muitos teóricos da saúde pública, uma razão tão importante quanto a avaliação da qualidade do sangue: abrir espaço para a educação de pessoas portadoras do traço falciforme sobre o risco reprodutivo de gerarem crianças com anemia falciforme 22 . Esse processo, no qual as pessoas são testadas e informadas sobre as características genéticas que possuem, tem sido chamado de aconselhamento genético 23 .

\section{O aconselhamento genético no centro de doação de sangue}

Toda pessoa doadora de sangue submete-se a uma bateria de exames que avalia a qualidade do seu sangue. Uma vez identificada qualquer alteração infecciosa, o procedimento padrão é o seu encaminhamento para um centro de saúde especializado. Para o traço falciforme, no entanto, há uma rotina de aconselhamento estruturada no próprio centro de doação de sangue. $\mathrm{O}$ aconselhamento genético é realizado em grupos com cerca de dez pessoas, ocasião em que são entregues os resultados dos exames pré-doação. O convite para o aconselhamento genético é feito por meio de uma carta enviada à residência declarada no formulário de triagem para a doação de sangue. Em geral, a carta é recebida cerca de duas semanas após a doação, quando apenas os resultados deveriam ser remetidos por correio.

A carta, embora apresente um breve agradecimento pela dádiva da doação, não vem acompanhada dos resultados dos exames, tal como ocorre com as pessoas consideradas saudáveis, e destina-se a informar que os testes laboratoriais constataram a presença de uma determinada característica genética: “... foi detectado em seu exame um tipo menos comum de hemoglobina, $a$ hemoglobina AS. Casos como o seu ocorrem em três (3\%) por cento da população. Esta condição é transmitida através do pai ou da mãe, que transmitem o gene $S$ para os filhos. A pessoa que tem esta hemoglobina é normal e não evolui para uma anemia mais forte (porém, pode ter filhos com anemia falciforme). Os demais testes foram normais...". A carta informa ainda que a entrega dos exames está condicionada à presença na sessão de aconselhamento genético, uma exigência não prevista no formulário pré-doação. Na verdade, a mera existência do aconselhamento genético não foi mencionada em nenhuma das fases do processo de doação de sangue, não tendo havido qualquer consentimento prévio, por parte do doador, em submeter-se ao aconselhamento. $\mathrm{O}$ aconselhamento torna-se, então, compulsório e, como a carta já anuncia, um dos principais objetivos será a informação sobre o risco reprodutivo.

Para muitas pessoas que vivenciam essa experiência, a carta representa a primeira fonte de informação sobre um traço genético que, muito embora esteja presente em seu corpo e seja hereditário, era desconhecido. A carta solicita que o doador procure o centro de doação de sangue em uma data específica e, na ocasião, informe que é portador do traço falciforme. A carta representa um verdadeiro divisor de águas na identidade do doador: a partir daquele momento sua identidade está vinculada à alteração genética encontrada em seu sangue. Seu retorno ao centro de doação não será mais na condição de um solidário cidadão que doou sangue, mas como alguém marcado pela genética. Um dos maiores desafios éticos da nova genética, especialmente em sua inserção na saúde pública, é exatamente evitar que a identidade individual seja reduzida às características genéticas. Por isso, muitos teóricos da bioética propõem que o direito de desconhecer a informação genética deva ser a condição ética para o funcionamento de qualquer programa de aconselhamento genético, um pres- 
suposto, infelizmente, desconsiderado pelo centro de doação de sangue 24 .

O responsável pelo aconselhamento genético é um médico hematologista, apesar de vários membros da equipe de saúde terem acesso aos dados dos prontuários dos doadores portadores do traço falciforme. Os objetivos da sessão de aconselhamento genético são basicamente dois. O primeiro objetivo é informar sobre o que representa o traço falciforme no contexto da doação de sangue. As pessoas são esclarecidas sobre as limitações do uso hemoterápico do sangue com o traço falciforme e desestimuladas a realizar futuras doações em virtude da impossibilidade de se aproveitar, integralmente, o sangue doado. O segundo objetivo é fornecer orientações sobre cuidados reprodutivos, enfatizando-se o risco de nascimento de futuras crianças com anemia falciforme. Um dos pontos marcantes da ênfase na reprodução durante o aconselhamento é a proposta de que outras pessoas da família, em especial cônjuges ou futuros cônjuges, devam ser também testadas.

As sessões de aconselhamento genético em grupo, nas quais a privacidade dos doadores não é preservada, e o sigilo sobre a informação genética deixa de existir, são defendidas, pela equipe de saúde do centro de doação de sangue, como uma estratégia educativa eficaz. Supõe-se que a experiência coletiva gere conforto moral para os doadores, pelo mero confronto e contato com outras pessoas em situação semelhante. $\mathrm{O}$ fato de essas pessoas, hipoteticamente, reconhecerem-se como uma coletividade de geneticamente iguais geraria uma experiência de solidariedade entre os doadores, atenuando o impacto dos resultados. Na verdade, esse pressuposto não foi jamais confrontado por qualquer análise sobre o efeito moral do aconselhamento coletivo na vida dessas pessoas, e os registros etnográficos da pesquisa apontam para outra direção. $\mathrm{O}$ aconselhamento coletivo converte-se em um momento de extremo constrangimento para os doadores, pois não apenas traços de identidade genética são explicitados, mas informações sobre raça e reprodução são também negociados.

\section{Nova genética, privacidade e confidencialidade}

Um dos grandes desafios da nova genética é garantir a credibilidade moral da prática do aconselhamento genético na saúde pública 25 . Após as denúncias dos abusos praticados pela medicina nazista em nome de ideais eugênicos, ou mesmo após as primeiras iniciativas de mapeamento genético populacional feitas nos anos 70, a informação genética passou a ser considerada perigosa para decisões políticas no campo da saúde. A nova genética acredita poder evitar o renascimento do autoritarismo eugênico pelo apelo a princípios éticos da cultura dos direitos humanos, tais como a autonomia individual, o pluralismo moral e a privacidade. A formação de um aconselhador genético, por exemplo, inclui tanto uma formação em genética, quanto um treinamento moral pautado em princípios éticos humanistas, tais como o exercício da tolerância e a promoção da liberdade 26,27,28.

$\mathrm{O}$ aconselhamento genético pode ser definido como uma prática a meio caminho do serviço social e da clínica médica. Na mesma medida em que está a qualidade da informação técnica transmitida sobre diagnósticos, probabilidades e riscos, está a habilidade do aconselhador em avaliar e compreender o impacto moral da informação genética na vida das pessoas. Por isso, um dos valores centrais do ethos do aconselhamento genético é a neutralidade moral, um princípio de dificílima concretização, mas que remete ao compromisso da nova genética com a autonomia individual ${ }^{9}$. Se, por um lado, a informação genética é parte da gênese individual e, portanto, deve ser tratada como algo privado, é, por outro, também, uma informação familiar 29. Esta tensão sobre a quem pertence a informação genética foi extensamente discutida nos primeiros anos de estruturação do aconselhamento genético, e, nesse contexto, os princípios da privacidade e da confidencialidade vêm sendo considerados referências éticas obrigatórias para a rotina de um bom aconselhamento.

O tema da confidencialidade é tão antigo quanto a própria prática médica. A garantia da confiança entre médico e paciente é um pressuposto tão central para o exercício da medicina que esse é um tema regulamentado por inúmeros códigos legais e éticos nacionais e internacionais. As legislações oscilam entre a total obrigatoriedade do segredo, na linha argumentativa de Kottow 30 que sustenta ser a confidencialidade um princípio "tudo ou nada", até previsões específicas de quebra do segredo, em casos de risco de vida ou de imposições legais 31 . O surgimento da nova genética, com as particularidades inerentes à informação genética, reacendeu o debate ético sobre a centralidade da confidencialidade para o atendimento em saúde.

No caso do centro de doação de sangue, o respeito à privacidade e a garantia da confidencialidade são princípios imperativos. O doador 
não é uma pessoa doente ou em busca de serviços de saúde. O doador é alguém que, motivado pela solidariedade, participa da dádiva da doação de sangue 11,32. A doação de sangue é comparada à experiência da dádiva, tal como descrita por Mauss 33 e Levi-Strauss 34, em que a troca simbólica é o objetivo da relação social. No Brasil, são os doadores que mantêm o sistema ativo, pois a comercialização do sangue é proibida 10 . Além disso, muito embora a motivação de alguns doadores seja suprir a necessidade de sangue de alguma pessoa em particular, a doação direta não é permitida, o que faz da doação um ato de solidariedade pública e não um ato de mera cumplicidade privada.

Em nome dessa particularidade do papel ocupado pelo doador no ciclo da política do sangue é que qualquer exposição de sua intimidade deve ser também entendida como uma questão de saúde pública, pelo risco de outros doadores sentirem-se desestimulados à doação. Alguns autores consideram ser essa uma avaliação conseqüencialista do risco que acompanha a quebra da privacidade, pois a garantia da confidencialidade é também uma forma de proteção do atual sistema de assistência à saúde 35,36. Na verdade, o questionário de triagem pré-doação, muito embora necessário do ponto de vista da garantia da qualidade do sangue, é, por si mesmo, um desestímulo à doação futura. A exigência da verdade sobre temas moralmente íntimos é reforçada pelo termo de consentimento final assinado pelo doador, no qual se notifica que qualquer omissão ou inverdade é passível de responsabilidade penal: “...autorizo a utilizarem o sangue por mim doado, de acordo com a legislação vigente, sem qualquer forma de comercialização. Declaro que o informado é verdadeiro sob pena de responder legalmente por omissão ou falsificação de algum fato...".

Diferentemente de outras situações terapêuticas, nas quais a confissão é uma prerrogativa para o bom atendimento, na doação de sangue, a confissão é uma exigência penal. É preciso que o doador fale a verdade, mesmo sobre temas restritos à sua privacidade ou até sobre práticas criminosas, como uso de drogas injetáveis ou realização de abortos. É verdade que o doador consente com essa exposição de sua intimidade no questionário pré-doação, mas uma breve análise das atitudes e comportamentos durante a fase de preenchimento do questionário é suficiente para compreender o quanto essas são informações que dizem respeito à intimidade e à dignidade de cada pessoa. O preenchimento é feito individualmente, e os doadores esforçam-se por impedir que ou- tras pessoas tenham, por descuido, qualquer acesso às suas informações. Entre os doadores, é possível observar, no instante de preenchimento, um silêncio absoluto e a repetição de uma mímica corporal em que o questionário fica a tal ponto protegido dos olhares indiscretos que é difícil visualizá-lo entre as mãos dos doadores.

Mas, se, por um lado, é certo afirmar que o doador consente com os testes pré-doação, por outro, é também possível invocar que há um acordo tácito de que a informação gerada pelos exames será protegida. O questionário prédoação explicita o caráter confidencial das informações ao afirmar que “...este questionário é sigiloso, e as informações são importantes para completar os exames necessários à utilização do seu sangue...". É preciso, portanto, haver obrigações de confidencialidade em todas as fases do ciclo dádiva-confissão-aconselhamento. Segundo Beauchamp \& Childress 37 (p. 456), “...a confidencialidade está presente quando uma pessoa revela uma informação a outra - seja por meio de palavras ou de um exame médicoe a pessoa a quem a informação é revelada promete não divulgar a um terceiro sem permissão...”. A informação confidencial é fornecida de forma privada e voluntária, tal como ocorre no questionário pré-doação, numa relação em que se pressupõe a confiança. A permissão que o doador concede é para o uso terapêutico da informação fornecida e gerada pelos exames, e não para o aconselhamento genético coletivo tal como é realizado.

Um dos argumentos contrários ao cumprimento estrito do princípio da confidencialidade sugere que, em situações que envolvam interesses vitais para outras pessoas, é possível romper com o segredo. A epidemia do HIV/ AIDS foi paradigmática para esse debate, fazendo com que inúmeros casos fossem discutidos em suas particularidades 38 . Mas mesmo nesses casos-limite, em que a vida de outras pessoas poderia estar em jogo em relação à manutenção do segredo, um dos poucos consensos éticos alcançados foi o de que os profissionais de saúde teriam a obrigação de procurar formas alternativas de prevenir os danos, antes da opção pela quebra da confidencialidade $35,37,39$. E, nesses casos excepcionais de quebra de confidencialidade, o ônus argumentativo recairia sobre aquele que rompesse o acordo de confiança 40. Ora, não apenas a informação sobre o traço falciforme não acarreta riscos de vida a outras pessoas, como não foram tentadas alternativas à quebra da privacidade e da confidencialidade antes do aconselhamento coletivo. 
Para determinar quando e sob que circunstâncias a confidencialidade pode ser rompida, é preciso estabelecer uma matriz de avaliação de riscos, em que a magnitude do dano e a sua probabilidade de concretização são algumas das variáveis a serem avaliadas 37 . No caso do traço falciforme, afora as limitações hemoterápicas do sangue com hemoglobinas AS que justificam o descarte parcial do sangue doado, não há dano imediato para o doador, tampouco para as pessoas a ele relacionadas. $\mathrm{O}$ único risco passível de ser mensurado para o doador seria da ordem de $25,0 \%$ de gerar uma criança com anemia falciforme, caso sua cônjuge também seja portadora do traço falciforme. Mesmo para o caso de um risco reprodutivo, para o qual a mensuração necessitaria da informação genética de outra pessoa, não seria possível falar diretamente em dano para o doador ou para qualquer pessoa a ele vinculada.

Intuitivamente, considera-se que o risco futuro de nascimento de uma criança com anemia falciforme seria razão suficiente para a quebra da privacidade e para a obrigatoriedade do aconselhamento genético. Esse argumento apresenta uma falácia contra-factual que não pode ser sustentada. Não existe dano decorrente das decisões reprodutivas de casais portadores do traço falciforme com o nascimento de uma criança com anemia falciforme. Não há dano a ser evitado, pois a única possibilidade de prevenção representa a impossibilidade de nascimento de uma futura pessoa com anemia falciforme 41,42. Para essa pessoa, não pode ser inferido dano, pois a vida com anemia falciforme é a condição de sua existência, e, como o aborto seletivo no Brasil não é permitido, futuras contestações judiciais de "vida injusta" são bastante restritas. Isso não quer dizer, no entanto, que não possam ser realizados outros julgamentos de ordem ética, como o de responsabilidade ou justiça, mas que não são os argumentos que justificam o aconselhamento coletivo pelos profissionais do centro de doação de sangue 43,44,45.

Várias foram as razões éticas alegadas pelo centro de doação onde foi realizada a pesquisa para sustentar a quebra da privacidade e da confidencialidade no trato da informação genética sobre o traço falciforme. Algumas foram de ordem administrativa, pois se argumentava a ausência de profissionais capacitados e disponíveis para ministrar sessões de aconselhamento individual; outras foram de ordem moral, pois se supunha que o aconselhamento em grupo geraria conforto moral às pessoas. $\mathrm{Na}$ verdade, o acompanhamento das sessões de aconselhamento genético mostrou que nenhum desses argumentos era razão suficiente para a quebra da privacidade. Se, por um lado, a privacidade não era um compromisso ético consolidado pela equipe de profissionais do centro de doação, por outro, a ânsia para informar o maior número de pessoas sobre o risco reprodutivo para a anemia falciforme era o fundamento ético das sessões de aconselhamento.

A obrigatoriedade do aconselhamento genético baseava-se na suposição de que a informação genética permite um maior controle do acaso. Pautado pelo argumento do senso comum segundo o qual "quanto mais informação, melhor”, o centro de doação via, no aconselhamento, uma prática de empoderamento dos doadores pela educação para o risco reprodutivo. Acrescida a essa expectativa, deve somar-se à noção biomédica de que o melhor diagnóstico é aquele realizado precocemente um valor potencializado pela nova genética 46 . Não se supunha que a informação sobre o risco ou mesmo que a exposição pública da identidade genética poderia acarretar danos aos doadores. A expectativa do centro era de que, após o aconselhamento, os doadores estariam capacitados para realizar suas escolhas reprodutivas, um raciocínio que pressupõe que as pessoas incorporariam, em seus projetos reprodutivos, a moralidade do risco genético. Sequer se cogitava a possibilidade de algumas pessoas optarem, deliberadamente, por ignorar o discurso biomédico sobre o risco, especialmente quando esse pressupõe a aceitação da racionalidade do controle reprodutivo para sua eficácia 47 .

A discussão bioética sobre o direito de desconhecer a informação genética ganhou fôlego nos anos 90, sendo os argumentos de Rhodes 48 paradigmáticos para compreender a força do pressuposto de que informação é sempre bemvinda. Rhodes defende que o dever de ser informado é condição de possibilidade para o exercício da autonomia, pois somente uma pessoa devidamente informada estaria capacitada para realizar escolhas. A conseqüência da relação entre o dever de ser informado e a autonomia pressupõe “...a inexistência do direito de permanecer ignorante...” 48 (p. 18). O argumento é basicamente circular: a autonomia pressupõe informação, e informação configura-se como um dever moral que antecede a tomada de decisões. A conclusão dessa correlação entre informação e autonomia, segundo a defesa de Rhodes, é que ignorar informações disponíveis equivale a escolher o acaso em detrimento da autonomia. Intuitivamente, esse foi o mesmo argumento utilizado pelo centro de doação para justificar o caráter compulsório do aconselhamento. 
$\mathrm{O}$ argumento filosófico de que ninguém tem o direito moral à ignorância genética carrega consigo dois pressupostos que não se prestam à contestação etnográfica. $O$ primeiro é o pressuposto de que as pessoas ambicionam acumular informações que lhes permitam melhor controlar e fundamentar suas decisões e, conseqüentemente, o futuro. A baixa procura pelos testes preditivos para doença de Huntington, por exemplo, mostrou o quanto essa era uma expectativa estritamente baseada na racionalidade do controle biomédico, e não no modo como as pessoas desejavam regular suas vidas 49 . O segundo pressuposto é que a biomedicina seria a fonte na qual as pessoas retirariam as informações necessárias para o controle do acaso. Ora, não apenas a biomedicina é somente uma dentre as inúmeras narrativas utilizadas para a explicação do fenômeno saúde e doença, como muitas dessas narrativas são anteriores à tentativa de genetização da reprodução 50 .

\section{Considerações finais}

A descrição etnográfica do processo de aconselhamento genético a que os doadores de sangue são compulsoriamente submetidos mostra o quanto a confidencialidade deve manter-se como um princípio central para a biomedicina. Se, por um lado, o dever da confidencialidade garante a privacidade e estimula a honestidade na relação entre o profissional e os usuários do sistema de saúde, por outro, somente uma estrutura baseada na ética do respeito à confidencialidade é que acolherá atos de solidariedade como a doação de sangue. O estudo de caso sobre a doação de sangue e o aconselhamento coletivo mostra como a garantia da confidencialidade no trato da informação genética deve ser entendida como uma questão de direitos humanos, mas também de saúde pública.
Isso não quer dizer que a confidencialidade deva ser um princípio absoluto. Pode haver casos em que a exigência da quebra do segredo seja ainda mais imperativa que o respeito à confissão. Mas a quebra da confidencialidade pressupõe alguns procedimentos também de ordem ética. No caso do centro de doação de sangue, a possibilidade da quebra do sigilo deveria estar prevista por ocasião do estabelecimento da situação de confidencialidade, ou seja, ainda na fase de preenchimento do questionário pré-doação. O segundo procedimento é que o aconselhamento deveria ser um serviço ofertado durante a fase de preenchimento do questionário pré-doação, ocasião em que o doador consentiria ou não em participar, e jamais condicioná-lo à entrega dos resultados dos exames. Por fim, é fundamental reconhecer que todos os profissionais envolvidos nos cuidados de saúde devem ser sensibilizados e treinados para a ética da confidencialidade e não apenas os médicos.

Há uma tendência a considerar a informação genética um caso excepcional para a análise da ética da confidencialidade. Muito embora existam particularidades morais na informação genética, tão decisiva quanto a qualidade da informação é a análise da situação em que a informação foi gerada. No caso do centro de doação de sangue, a informação sobre o traço falciforme foi resultado de uma situação de dádiva, a partir de uma expressão de solidariedade em que se pressupõe tacitamente a confiança mútua. A análise da situação em que a informação foi gerada deve garantir ainda a promessa de manter a informação na situação original, ou seja, o privilégio da confissão não significa a posse da informação para outros fins que não os previamente autorizados. Por fim, é importante lembrar que, dentre as situações de excepcionalidade que justificariam uma quebra de confidencialidade, estão aquelas que preveniriam danos graves, mas não ações que busquem apenas promover escolhas informadas ou imputar responsabilidades reprodutivas. 


\section{Resumo}

A anemia falciforme é a doença genética com maior prevalência no Brasil. Desde 1976, recomenda-se que o exame para identificação do traço falciforme faça parte do protocolo de triagem de doadores de sangue, sendo esse um dos mecanismos mais eficazes de identificação genética em saúde pública para as alterações falciformes no país. Por meio de um estudo etnográfico sobre o aconselhamento genético ministrado às pessoas identificadas como portadoras do traço falciforme em um dos principais centros de doação de sangue, este artigo defende que a confidencialidade no trato da informação genética deve ser entendida como uma questão de saúde pública assim como de direitos humanos.

Anemia Falciforme; Aconselhamento Genético; Bioética

\section{Colaboradores}

D. Diniz foi responsável pela revisão da bibliografia internacional e pela redação final do artigo. C. Guedes foi responsável pela etnografia, pela revisão da bibliografia em língua portuguesa e pela revisão final do artigo.

\section{Agradecimentos}

Este artigo é resultado de uma pesquisa ampla sobre anemia falciforme, direitos reprodutivos e bioética no Brasil, apoiada pela Fundação Ford e pelo Conselho Nacional de Pesquisa Científica e Tecnológica.

\section{Referências}

1. Brasil. Lei n. 1.075. Dispõe sobre doação voluntária de sangue. Diário Oficial da União 1950; 27 mar.

2. Ramalho A. Hemoglobina S em doadores de sangue brasileiros. AMB Rev Assoc Med Bras 1976; 22:467-8.

3. Angastiniotis M, Kyriakidou S, Hadjiminas M. Como se ha combatido la talasemia en Chipre. Foro Mund Salud 1986; 7:312-9.

4. Dorticos-Balea A, Martin-Ruiz M, HechevarriaFernandez P, Robaina-Castellanos MS, RodriguezBlanco M, Moras-Bracero F, et al. Reproductive behavior of couples at risk for sickle cell disease in Cuba: a follow-up study. Prenat Diagn 1997; 17:737-42.

5. Tapper M. In the blood: sickle cell anaemia and the politics of race. Philadelphia: University of Pennsylvania Press; 1999.

6. Anionwu E, Atkin K. The politics of sickle cell and thalassemia. Buckingham: Open University Press; 2001.

7. Wailoo K. Dying in the city of the blues: sickle cell anemia and the politics of race and health. Chapel Hill: University of North Carolina Press; 2001.

8. Ramalho A, Magna L, Paiva-e-Silva R. A Portaria no 822/01 do Ministério da Saúde e as peculiaridades das hemoglobinopatias em saúde pública no Brasil. Cad Saúde Pública 2003; 19:1195-9.

9. Davis D. The ethics and ethos of genetic counseling. In: Davis D, editor. Genetic dilemmas: reproductive technology, parental choices, and children's futures. New York: Routledge; 2001. p. 9-34.

10. Brasil. Portaria n. 343. Aprova regulamento técnico para a obtenção, testagem, processamento e controle de qualidade de sangue e hemocomponentes para uso humano. Diário Oficial da União 2002; $13 \mathrm{dez}$

11. Guedes C. Bumerangues vermelhos: o direito à doação de sangue na perspectiva da pessoa portadora do traço falciforme [Monografia de Graduação]. Brasília: Instituto de Ciências Humanas, Universidade de Brasília; 2002.

12. Zago M. Considerações gerais. In: MacDowell B, organizadora. Manual de diagnóstico e tratamento de doenças falciformes. Brasília: Agência Nacional de Vigilância Sanitária; 2002. p. 7-11.

13. Naoum P, Angulo I, Brandão A, Graciano R, Spir M, Nomura E, et al. Detecção e conscientização de portadores de hemoglobionopatias nas regiões de São José do Rio Preto e Presidente Prudente, SP (Brasil). Rev Saúde Pública 1985; 19:364-73.

14. Naoum P. Prevalência e controle da hemoglobina S. Rev Bras Hematol Hemoter 2000; 22:142-8.

15. Paiva-e-Silva R, Ramalho A, Cassorla R. A anemia falciforme como problema de saúde pública no Brasil. Rev Saúde Pública 1993; 27:54-8.

16. Diniz D, Guedes C. Anemia falciforme: um problema nosso. Uma abordagem bioética sobre a nova genética. Cad Saúde Pública 2003; 19:1761-70.

17. Modell B. Etica del diagnóstico prenatal y asesoramiento genético. Foro Mund Salud 1990; 11:17986.

18. Fost N. Ethical implications of screening asymptomatic individuals. FASEB J 1992; 6:2813-7. 
19. Zago M. Anemia falciforme e doenças falciformes. In: Hamann E, Tauil P, organizadores. Manual de doenças mais importantes, por razões étnicas, na população afro-descendente. Brasília: Secretaria de Políticas da Saúde, Ministério da Saúde; 2001. p. 13-35.

20. Morais J, Martins J, Vieira M. Falcização em concentrados de hemácias provenientes de doadores com hemoglobinas armazenadas em condições normais de banco de sangue. Rev Med Univ Fed Ceará 1987; 25:63-9.

21. Marques Jr. J. Transfusão de hemácias contendo hemoglobina S. Bol Soc Bras Hematol Hemoter $1994 ; 16: 229-32$.

22. Paiva-e-Silva R. Efeitos da orientação genética fornecida a doadores de sangue com o traço falciforme: riscos e benefícios [Tese de Doutorado]. Campinas: Faculdade de Ciências Médicas, Universidade Estadual de Campinas; 1995.

23. Paiva-e-Silva R, Ramalho A. Riscos e benefícios da triagem genética: o traço falciforme como modelo de estudo em uma população brasileira. Cad Saúde Pública 1997; 13:285-94.

24. Beck U. Sobre a incompreendida falta de experiência da genética humana e as conseqüências sociais do não-saber relativo. In: De Boni L, Jacob G, Salzano F, organizadores. Ética e genética. Porto Alegre: EDIPUCRS; 1998. p. 39-62.

25. Atkin K, Ahmad W. Genetic screening and haemoglobinopathies: ethics, politics and practice. Soc Sci Med 1998; 46:445-58.

26. Raap R. Chromosomes and communication: the discourse of genetic counseling. Med Anthropol Q 1988; 2:143-57.

27. Raap R. Testing women, testing the fetus: the social impact of amniocentesis in America. New York: Routledge; 1999.

28. Bartels D, Leroy B, Caplan A, editors. Prescribing our future: ethical challenges in genetic counseling. New York: Aldine De Gruyter; 1993.

29. Heyd D. Genethics: moral issues in the creation of people. Berkeley: University of California Press; 1992.

30. Kottow M. Medical confidentiality: an intransigent and absolute obligation. J Med Ethics 1986; 12:117-22.

31. Mason JK, McCall-Smith RA. Law and medical ethics. London: Butterworths; 1999.

32. Levine $\mathrm{C}$. The community blood supply and patients' choice. Hastings Cent Rep 1987; 17:5.

33. Mauss M. Sociologia e antropologia. v. II. São Paulo: EPU/Edusp; 1974.
34. Levi-Strauss C. Introdução à obra de Marcel Mauss In: Mauss M, organizador. Ensaio sobre a dádiva. Lisboa: Edições 70; 1950. p. 9-46.

35. Gillon R. Confidentiality. In: Kuhse H, Singer P, editors. A companion to bioethics. Oxford: Blackwell Publishers; 1998. p. 425-31.

36. O'Brien J, Chantler C. Confidentiality and the duties of care. J Med Ethics 2003; 29:36-40.

37. Beauchamp T, Childress J. O relacionamento entre profissional e paciente. In: Beauchamp T, Childress J, organizadores. Princípios de ética biomédica. São Paulo: Loyola; 2001. p. 425-94.

38. Gillet G. AIDS and confidentiality. J Appl Philos 1987; 4:15-20.

39. Brazier M. A relationship of trust and confidence. In: Brazier M, editor. Medicine, patients and the law. London: Penguin Books; 1992. p. 44-67.

40. Bok S. The limits of confidentiality. Hastings Cent Rep 1983; 13:24-31.

41. Brock D. The non-identity problem and genetic harms. Bioethics 1995; 9:269-75.

42. Brock D. Obligaciones éticas para prevenir daños transmitidos geneticamente. In: Hansberg O, Platts M, organizadores. Responsabilidad y libertad. México DF: Fondo de Cultura Económica; 2002. p. 49-67.

43. Steinbock B, McClamrock R. When is birth unfair to the child? Hastings Cent Rep 1994; 24:15-21.

44. Buchanan A, Brock D, Daniels N, Wikler D. From chance to choice: genetics and justice. Cambridge: Cambridge University Press; 2000.

45. Andre J, Fleck L, Tomlinson T. On being genetically “irresponsible”. Kennedy Inst Ethics J 2000; 10:129-46.

46. Hepburn E. Genetic testing and early diagnosis and intervention: boon or burden? J Med Ethics 1996; 22:105-10.

47. Sommerville A, English V. Genetic privacy: orthodoxy or oxymoron? J Med Ethics 1999; 25:144-50.

48. Rhodes R. Genetic links, family ties, and social bonds: rights and responsibilities in the face of genetic knowledge. J Med Philos 1998; 23:10-30.

49. Wexler N. Mapping fate: a memoir of family, risk, and genetic research. Berkeley: California University Press; 1996.

50. Richards M. Families, kinship and genetics. In: Marteau T, Richards M, editors. The trouble helix: social and psychological implications of the new human genetics. Cambridge: Cambridge University Press; 1996. p. 249-73.

Recebido em 08/Abr/2004

Versão final reapresentada em 07/Out/2004

Aprovado em 04/Nov/2004 